\title{
The Role of Web-Based Learning Environments in Fostering Collaboration
}

\author{
Jasna Kuljis and Lorna Lines \\ School of Information Systems, Computing \& Mathematics \\ Brunel University, West London \\ Uxbridge, UB8 3PH, United Kingdom \\ \{Jasna.Kuljis, Lorna. Lines\} @brunel.ac.uk
}

\begin{abstract}
Web-based learning environments are increasingly used to support lecture and seminar activities in blended learning courses and there is growing evidence to suggest a positive relationship between peer-to-peer learning activities and academic attainment. The role of web-based learning environments that are used as a learning-support tool is considered where the blended learning system goals of social interaction and personal agency within the context of web-based discussion boards are of particular interest. Using web-based learning community discussions as a case study we illustrate the role of personal agency and social interaction and how personalisation of the learning experience may be supported by the teachers. Our results are intended to inform teachers and the design of automated instructional agents, that will need to support personal agency and social interaction, to facilitate online student collaboration within the blended learning system context.
\end{abstract}

Keywords: Blended learning, collaborative learning, online discussion, discussion group development.

\section{Introduction}

The integration of web-based learning applications within traditional, face-to-face learning systems is growing rapidly with Higher Education Institutions in United Kingdom. Few guidelines are available within the literature to support such course designs and delivery due to the complexity of student and tutor needs, subject domain and the availability and maintenance of technological infrastructures. Rather, the pedagogical literature presents case studies that are considered to report 'best practice', usually providing an account of blended learning system designs that have been created on an ad hoc basis leaving the reader to discern the applicability of techniques and approaches in developing their own appropriate blended learning systems. Here, it is recognised that to provide a one-size-fits-all approach to the design of blended learning systems is inherently complex, and potentially futile, given the observed variety in blended learning sophistication. Our position is that although the one-size-fits-all approach is ambitious, as a learning community we may be able to guide designers of blended learning systems with specific learning components; a common trend in the current literature, whereby the focal point for discussion and 
subsequent guidance may be, for example, the learning impacts offered by the use of web-based applications to support virtual classrooms [1] group work [2] and discussion boards [3].

Social interaction and personal agency are critical goals within any blended learning system. These goals may be supported through the use of web-based asynchronous discussion boards, whereby participation within the discussion is encouraged but not compulsory. Thus the goal of social interaction is promoted and supported and the goal of personal agency, through activities such as student choice and empowerment, is fostered. Of particular interests here, is how discussions are initiated, and personal agency developed.

To further the development of blended learning systems, this paper considers the role of asynchronous discussion boards within encouraged, but non-compulsory, student-to-student collaborations in problem solving activities. Having reported the benefits of adopting a blended learning approach to course design and delivery and identified the role of web-based discussion boards as an 'opt-in' personalisation feature, to support the blended learning goals presented by [4], [5] of social interaction and personal agency, are considered. Using discussion data collected from non-compulsory discussion board collaboration activities undertaken by a first year group of BSc (Hons) Computer Science and Information Systems students at Brunel University in the UK, the purpose of this paper is to identify discussion group development and a specific set of guidelines for tutors using discussion boards as a feature of their blended learning system approach.

\section{A Blended Learning Approach}

Blended learning systems integrate both face-to-face and online learning experiences and are inherently complex [6]. Student and teachers' needs, subject domain, and resources are all likely to impact the composition of blended learning systems and the achievement, or not, of enhancing the learning experience [6]. We take the position that the student should be the central component of any learning system, blended, or otherwise.

There is strong evidence to suggest that the success of blended learning systems lies in the integration of the online learning and face-to-face learning components during course design and delivery (see [5]). Good systems achieve the ultimate goal of enhancing student learning through utilising the strengths of face-to-face learning systems to counter weaknesses of online learning systems, and vice versa. For example, using a blended learning approach, face-to-face learning components are likely to include more group discussions and question and answer sessions between students and their teachers, which overcomes the relative weakness associated with isolation due to the lack of face-to-face communication activities. In contrast, self-test activities may be better suited to an online blended learning component as these could consume valuable time within seminars that could be more usefully employed to hold theoretical discussions or conduct practical activities.

Although 'integration' of the two learning system components (online and face-toface) is critical, there are few guidelines within the pedagogical literature on how to do this. This may simply be due to the variety of courses, subject domains and disciplines. Due to blended learning novelty and complexity, current research is based 
predominantly on case study reports for course designers to review and elicit salient points of best-practice for the learning needs of their students, the subject domain and their course management requirements.

However, although complexity in design and delivery is reported, the ultimate goals of blended learning appear to remain relatively simple and consistent. Osguthorpe and Graham [4] outline six goals of blended learning that permeate throughout the literature and are summarised as follows; pedagogical richness achieved by improvements to student learning; access to knowledge achieved through the accessibility of course content and materials that assist students' when demonstrating understanding, application and critical evaluation skills; social interaction which is measured as product of social operation through sharing and questioning learning experiences and activities with peers and teachers; Personal agency achieved by the student being supported in controlling and directing their learning experiences, leading the student to a sense of empowerment and heightened motivation; Cost effectiveness achieved by appropriate management of costs relating to a) teachers' time/effort and b) funding for the technological infrastructure and upkeep, and; ease of revision that can be measured against cost, time and human resources required to introduce and/or modify course content, materials and delivery.

The achievement of pedagogical richness within a blended learning system can be measured in improvements to student learning. Such improvements will likely include objective measures of student attainment and subjective measures that consider the students' personal learning experiences. The blended learning system goals of social interaction and personal agency are primarily based on student centred activities, whereas cost effectiveness and ease of revision, appear to relate directly to course management activities.

The lack of social interaction is frequently cited as a complaint offered by students undertaking distance learning programmes (see [7]) whereby face-to-face interaction (if any) is limited and social isolation is experienced. Within a blended learning system that comprises both face-to-face and online components it would be reasonable to assume that any sense of social isolation is reduced in comparison to purely online, web-based, distance learning courses whereby students are geographically dispersed and face-to-face events are not supported within course design and delivery. However, what is also unclear in blended learning system development is whether social interaction, a critical goal and a positive contribution to the students' learning experience (see [4]), is a necessary activity within the online component of a blended learning system. Due to the positive effects on the student learning experience, we take the position that social interaction should be encouraged, but not necessarily enforced, within any learning system and its sub-components. Although student collaboration and discussion has been observed to be of merit for student satisfaction and in some cases, improved attainment (see [1]), this is not, in itself, justification for enforcing collaboration activities; especially when the goal of personal agency is considered.

The goal of personal agency is to provide students with the opportunity to choose learning system activities that best support their individual needs. By offering a sense of control over their learning system choices, the student then 'buys-in' and takes ownership of their participation. This commitment and identification of their own learning needs is likely to lead to greater reports of student satisfaction and student 
attainment as identified by Hiltz [1]. In practice, it is very difficult to meet all student learning needs while balancing the management of associated activities especially with large groups of students. However, with the additional tools that online learning applications now offer, such as virtual chat, discussion boards and videoconferencing, there is some opportunity within courses to support the goals of student interaction and personal agency simultaneously.

\subsection{Discussion Boards: Supporting Student-to-Student Collaboration}

The impetus on teachers who adopt a blended learning system is to strike the right balance between traditional face-to-face learning components and their choice of online learning components. Although discussion tools are offered as a positive feature of online learning tools, little is known as to how these discussion boards should be utilised to facilitate the goals of social interaction and personal agency. The literature tends to concentrate on the use of web-based discussion boards within the context of traditional distance learning courses that do not support face-to-face learning activities. Within the distance learning context, rather than discretionary use of discussion board features, the contribution to the discussion of each student may be monitored by the teachers, and/or contribution to the discussion may be compulsory (for example, see [7], [8]).

As supportive blended learning system features to be used to facilitate interactions outside of the classroom, we take the position that discussion board tools may be better placed as 'optional' learning system components that the student can opt-in to, rather than opting-out of. For a student to opt-out of using online discussion board facilities may be of equal detriment, if not greater, to enforcing interactions between students. By opting out of using the discussion board, the student is making a clear statement that they do not wish to participate. By allowing students to opt-in, they are less likely to fear reprimands from the teachers or their peers.

Thus, we liken this encouraged, but not enforced, use of an online discussion board within blended learning systems to wider ranging online applications, such as ecommerce sites and e-government sites that allow users to choose content and delivery design features to enhance their online experience.

\section{Case Study}

A case study approach was adopted using discussion board postings from a first year programming course Construction of Programs offered at Brunel University in the UK. This course is compulsory and the main emphasis of the course is object oriented programming principles using Java. The course employs the blended learning approach that combines formal face-to-face lectures and practical work undertaken in lab sessions together with extensive support provided via the WebCT learning platform [9]. We combined the strength of BlueJ, an interactive development environment designed explicitly as an environment to teach introductory objectoriented programming (hhtp://www.bluej.org) and WebCT.

There are 2 hour lectures plus 2 hours of structured lab activities a week over 24 weeks. The course is supported by a teaching team of tutors and graduate teaching assistants. Lectures are given in one session to all students enrolled on the course. 
Students are divided into smaller groups and each has a 2 hour lab session per week. To support lectures and labs, we use Barnes and Kölling [10] which focuses on the general object-oriented and programming concepts while integrating this with the use of the BlueJ environment. The course has a strong web resource base and all course material is available on WebCT including coursework online submissions, regular tests and quizzes, and an on-line discussion forum.

Throughout the course students are required to perform a lot of practical problems as well as to complete associated tests assessing their knowledge. Each week students are given practical exercises (made available on WebCT) that address the material presented during the lecture for that week. Typically, most of the students have been working on the given exercises during their lab sessions in the same week. Lab sessions are supported by a group of tutors and teaching assistants available to help with the problems. Students are asked to undertake the corresponding lab test upon the completion of lab exercises. Each lab test is made available for two weeks and students were given freedom to choose when to undertake the test. Most of these tests $(80 \%)$ were assessed and contributed $25 \%$ of the overall grade for the course. Students had information on which tests would be used for the assessment and how the tests would be graded and therefore put considerable effort to perform well on those tests. Students also had to put all acquired knowledge into practice through a substantial programming project which was assessed and contributed $25 \%$ towards their overall grade. The exam which contributes $50 \%$ towards the overall grade is a combination of multiple choice questions and problem solving questions to which students are expected to provide their own answers.

The on-line discussion forum on WebCT is a standard facility offered by WebCT in the form of threaded messages. It was used throughout the duration of the course to post notices to students. They were informed about its existence but no active effort was made to enforce any type of students' participation in the discussion forum apart from discouraging the use of email queries related to the course directed to individual tutors. Students were advised to post such queries to the WebCT discussion forum so that all students could benefit from the question/response and reduce the number of identical queries. Even though the members of the teaching team regularly check the discussion board and reply to posted questions, if or when relevant, student participation was neither monitored nor measured for any performance purpose. The decision to use the WebCT discussion forum was entirely the students'.

\subsection{Data Collection and Analysis}

WebCT offers course administrators an archive facility, whereby message boards can be downloaded and their content stored. The discussion board messages for 2003-04 were gathered via this archive technique and used for the subsequent analysis. All of the messages posted on the discussion board were subjected to a thematic analysis [11] whereby common themes based on, for example, message topic, function, and activity were identified within each message and grouped to obtain an understanding of the message-posting behaviours of both students and teaching team members. In total 726 messages were posted on the discussion board of which 612 messages were posted by students and 114 messages by the members of teaching team. Unsurprisingly discussion activity was observed to be at its most prolific immediately prior to the coursework deadline and examinations periods. 
Table 1. Messages by themes

\begin{tabular}{lll}
\hline Theme & All messages & Messages posted by students \\
\hline Organizational & 329 & 249 \\
Problem solving & 397 & 367 \\
Total number of messages & 726 & 616 \\
\hline
\end{tabular}

As an output of the thematic analysis, two major themes were observed as a) organization, and b) problem solving. Within the Organization theme nine subthemes were identified and seven Problem Solving sub-themes were observed. The number of messages in Problem Solving theme messages slightly outnumbers the messages in Organization theme (see Table 1). The number of problem solving messages was steady with an upwards trend through the period until March when the number of messages soared due to increased coursework activity that was due at the beginning of April. Similarly just before the examinations.

\subsection{Supporting Social Interaction and Fostering Personal Agency}

In a face-to-face learning setting there should be no problems in supporting social interaction. After all, requirements of physical presence on campus, at least for scheduled activities, such as lectures and lab sessions, inevitably would develop a sense of belonging to a group by its members. So, the question we should address is what prompts social interaction in an online environment? We have seen in our discussion so far that students voluntarily participated in the discussion forum and that they posted 616 messages in the period of 11 months. There was no pressure to use the WebCT discussion forum, the participation was not monitored and, most notably it did not affect assessment. So, why did the students participate? Was their classroom / lab based social interaction insufficient; what were the lacking aspects?

We tried to answer these questions through an analysis conducted on all recorded messages in the WebCT discussion forum for the course. First, we observed that less than half the class participated and that only 98 students from the class of 195 actively participated in the discussion. What motivated participation and what were the reasons for $50 \%$ abstentions we can only speculate? Whatever the reasons, these nonparticipating students may have reaped other people's efforts. The majority of active students (60 students) posted fewer than 5 messages, and only a very small minority (17 students) posted ten or more messages. In the cases where students posted ten or more messages we observed the following pattern; the majority of students initially sought information from the teachers, then from each other and then they started providing help. One can assume that this indicates that their confidence, and in turn their personal agency grew.

Table 2. Distribution of problem solving messages

\begin{tabular}{lll}
\hline Subject matter & All messages & Messages posted by students \\
\hline Coursework related & 205 & 189 \\
Lab exercises & 51 & 47 \\
Lab tests related & 69 & 66 \\
Exam related & 38 & 36 \\
\hline
\end{tabular}


The analysis of message categories indicates that assessment is the main concern of the most messages with the request for code or solution to the coursework project problem being the most frequently posted message. Coursework related organizational messages and general course related messages follow. Surprisingly the next most frequent category of messages is provision of code or solution as the response to a request and these were supplied for coursework related problems. This suggests that there indeed was a sense of community created by the discussion forum, as evidenced by the solicited and unsolicited help posted on WebCT. Even though students helped each other on a variety of messages we consider problem solving messages a primary source for observing the development of personal agency and table 2 illustrates the distribution of problem solving messages, whereas table 3 identifies the 'learning' role of the message posted.

Table 3. Students' collaboration on problem solving

\begin{tabular}{lr}
\hline Type of involvement & Number of messages \\
\hline Seeking help & 145 \\
Giving help (solicited) & 123 \\
Posting solutions (unsolicited) & 11 \\
Active collaboration on problem solving & 268 \\
\hline
\end{tabular}

Unsolicited messages were interesting; one can either assume that students posting them were either altruists or so proud of their achievements. However, our analysis is more concerned with the solicited help. Some students were very pragmatic members of the 'silent crowd' who only used the discussion forum when that was for their own benefit. Several of them in the process also shared some of their knowledge. From our analysis we can argue that the discussion forum tool offered on WebCT was instrumental in the formation of an online community. Students who were actively engaged in shaping this community obviously felt as its members as their behaviour demonstrated. Some members developed into specific roles through the engagement in the community. In particular one author was soon recognized as a benefactor by the members of the online community who often addressed their queries to him.

\section{Discussion}

Our case study illustrates the use of a threaded discussion forum offered by an online learning environment WebCT. We wanted to assess whether such discussion tools could not only support social interaction but also foster the development of personal agency; two critical blended learning goals. The course used in the case study has a strong problem-solving orientation and students are assessed on a variety of problemsolving activities throughout the teaching year. The course taught students how to approach problem solving using the Java programming language. We felt that the combination of the complexity of the subject and the difficulty many students experience in learning programming together, with continuous assessment based on problem solving activities encouraged students to collaborate. 
As already mentioned, in each week of term (course run over two terms) students were given a set of exercises to complete during the scheduled lab sessions and a test to attempt. Most students attempted all tests regardless whether or not tests were assessed. We deliberately did not provide solutions to lab exercises, lab tests, and to the previous years' examination papers to further encourage students to rely on their skills, to collaborate on problem solving activities, and be less dependent on their teachers. Members of the teaching team regularly monitored the ongoing discussions on WebCT and intervened when necessary. However, we did not reply to queries immediately unless the issues that rose required the response from one of the teachers. Most of the queries were left unanswered for a day or two so that other students might feel inclined to answer instead, which in most cases they did. We interfered only if the answers provided by other students were inaccurate, or if nobody made an attempt to answer, or sometimes to provide a broader view. That approach worked well and there were no complaints from students. The involvement of students in problem solving activity was gradual but towards the end of the course the forum was buzzing with constructive discussions.

Many students also worked together in small groups formed during scheduled lab sessions. However, such partnerships were not always successful, as sometimes groups formed by the academically weak students needed help from outside. Similarly, academically strong students often formed their own groups and there was not always interaction between these two types of groups. Given the blended learning environment and availability of real social interaction within the community created through attending lectures and lab session, the question is what prompted half of students to use the online discussion board to the extent that the development of personal agency could be observed. Some of the reasons are as follows:

- Many students work and have no time for social interactions, or have no flexibility with their free time;

- It is convenient to use the discussion forum, any time and anywhere (Internet);

- The immediacy of one-way communication - posting a message.

- In face-to-face interaction you need to know whom to ask which is not always obvious. In a virtual community questions are addressed to everybody who has access and chances are somebody coming with a solution to a problem are much higher;

- There is relative anonymity and hence less embarrassment for participants.

The above analyses complements the points made by [12] regarding asynchronous discussions. The idea of opting in to participating in discussion groups is supported by the trend towards learner control [13], where learners' choose the mechanisms, or rather, learning system sub-components.

There is evidence that the community was quite strong. It persisted well after the course was finished - it only stopped when students were denied access because of the need to prepare for the next year. What can we say about the 'silent crowd', the half of the students? There may be many reasons, such as shyness, anxiety, lack of confidence/time, information overload and/or poor motivation [14]. One of the challenges is to find mechanisms for increasing the proportion of participating students while providing the opportunity within a constructive, non-threatening environment to develop personal agency. 


\section{Conclusions}

This paper considers the role of asynchronous discussion boards within encouraged, but non-compulsory, student-to-student collaborations in problem solving activities. The analyses of messages posted on the discussion board on WebCT throughout the duration of a programming course indicated that students were indeed collaborating on problem solving activities. Assessment was the main concern of most messages.

Based on our experience and the evidence from the conducted analysis we give the following recommendations:

- The tutor role within the discussion should be perceived as facilitator, not provider. Resist 'spoon feeding' as it does not help develop personal agency nor independence of thought.

- Encourage, but do not enforce participation in online group discussions. Do not monitor student participation for assessment purposes as additional 'pressure' to perform may detract from the development of personal agency.

- Do not respond to student queries quickly to encourage community development.

- Step in only when there is a problem. For example, when there is no response to a student query; a repeated request or students are suggesting inappropriate ways of solving the problem.

Although we support the notion of non-compulsory participation within online discussion activities, caution in the use of a number of optional face-to-face and online learning system components, may negatively impact the students' learning experiences. Kay [13] warns that by providing the student with too much control over their learning activities, we may induce a sense of overload to the point of distraction, thus making any choices that the student has made regarding their learning preferences redundant.

The results reported here are intended to inform teachers attempting a blended learning approach as well as informing the design of automated instructional agents to facilitate online student collaboration within the blended learning system context. Our tutor recommendations support, in part, the activities to be conducted by the automatic peer as described in [15].

\section{References}

1. Hiltz, S.: Impacts of College-level Courses via Asynchronous Learning Networks: Some Preliminary Results. Journal of Asynchronous Learning Networks (1997) available: http://web.njit.edu/hiltz/workingpapers/philly/philly.htm

2. Gonzalez, M.G., Burke, M.J., Santuzzi, A.M., Bradley, J.C.: The Impact of Group Process Variables on the Effectiveness of Distance Collaboration Groups. Computers in Human Behaviour 12, 629-648 (2003)

3. Schellens, T., Valcke, M.: Collaborative Learning in Asynchronous Discussion Groups: What About the Impact on Cognitive Processing? Computers in Human Behaviour 21, 957-975 (2005)

4. Osguthorpe, R.T., Graham, C.R.: Blended Learning Environments: Definitions and Directions. The Quarterly Review of Distance Education 4, 227-233 (2003) 
5. Graham, C.R.: Blended Learning Systems: Definition, Current Trends, and Future Directions. In: Bonk, C.J., Graham, C.R. (eds.) Handbook of Blended Learning: Global Perspectives, Local Designs, Pfeiffer Publishing, San Francisco (2004)

6. Garrison, D.R., Kanuka, H.: Blended Learning: Uncovering its Transformative Potential in Higher Education. The. Internet and Higher Education 7, 95-105 (2004)

7. Clark, J.: Stimulating Collaboration and Discussion in Online Learning Environments. Internet and Higher Education 4, 119-124 (2001)

8. Corich, S., Kinshuk, L.T., Hunt, L.M.: Using Discussion Forums to Support Collaboration. In: 3rd Pan Commonwealth Forum on Open Learning, Dunedin, NZ (2004)

9. Kuljis, J.: Orienting the Teaching of an Introductory Object-oriented Programming to Meet the Learning Objective. Journal of Computing and Information Technology. 12, 135-142 (2004)

10. Barnes, D.J., Kölling, M.: Objects First with Java. A Practical Introduction Using BlueJ. Pearson, Harlow (2003)

11. Owen, W.F.: Interpretative Themes in Relational Communication. Quarterly Journal of Speech 70, 274-287 (1984)

12. McNeil, S.G., Robin, B.R., Miller, R.M.: Facilitating Interaction, Communication and Collaboration in Online Courses. Computers \& Geosciences 26, 108-699 (2000)

13. Kay, J.: Learner Control. User Modeling and User-Adapted Interaction. 11, 111-127 (2001)

14. Nonnecke, B., Preece, J.: Why Lurkers Lurk. In: Proceedings of Americas Conference on Information Systems. Boston (2001)

15. Goodman, B.A., Linton, F.N., Gaimari, R.D., Hitzeman, J.M., Ross, H.J., Zarrella, G.: Using Dialogue Features to Predict Trouble During Collaborative Learning. User Modeling and User-Adapted Interaction. 15, 85-134 (2005) 